\title{
Universal Human Rights? Breaking the Institutional Barriers Facing Climate-Vulnerable Small-Island Developing States
}

\author{
Alice Venn \\ PhD Candidate and Tutor, University of Bristol Law School \\ alice.venn@bristol.ac.uk
}

\begin{abstract}
There is a need to overcome the dichotomy in international responses to climate change between, on the one hand, a recognition of the significant threat posed by climate impacts for the continued enjoyment of fundamental rights, and, on the other, the lack of provision made for strengthening the legal protections available to climatevulnerable states. The question of access to human-rights mechanisms currently looms large as a limitation on legal action within, or by, Small-Island Developing States. This article, drawing on empirical research conducted in Vanuatu and Fiji, examines the entrenched institutional barriers to engagement with the core international human rights treaties in the South Pacific. A number of steps are proposed to guide action by the international community, through funding strategies, integrated vulnerability assessments, and targeted in-country capacity building, in order to enable more effective engagement with rights mechanisms and offer greater recourse to justice.
\end{abstract}

\section{Keywords}

Small-Island Developing States (sIDs) - South Pacific - institutional barriers - human rights - climate finance - capacity building

* This project received funding from the South West Doctoral Training Partnership of the UK Economic and Social Research Council (ESRC).

(C) ALICE VENN, 2017 | DOI 10.1163/18786561-00704005

This is an open access article distributed under the terms of the prevailing CC-BY License at the time of publication. 


\section{Introduction}

Small-Island Developing States are notoriously vulnerable to the impacts of climate change-from sea-level rise and storm surges, ${ }^{1}$ to increasingly intense tropical cyclones. ${ }^{2}$ At the COP 21 negotiations in Paris, human rights formed one of the core areas of focus for climate-vulnerable states. Human rights find expression in a preambular clause of the Paris Agreement, to the effect that the parties should 'respect, promote and consider their respective obligations on human rights' 3 in climate action. Nevertheless, human rights continue to be treated as ancillary safeguarding considerations in climate policy, as opposed to central components of an effective response.

The South Pacific region is home to some of the world's most climatevulnerable island nations, including four Least Developed Countries ${ }^{4}$ and five of the countries that are most exposed to, or at-risk of, natural disasters. ${ }^{5}$ Governments in the region have expressed their distress at the 'existential threats to our very survival and other violations of human rights' 6 resulting from climate change, while the threat posed to a broad range of rights has been reaffirmed by UN human rights bodies. ${ }^{7} \mathrm{~A}$ further significant threat is looming for the lowest-lying Pacific Island nations, which face complete inundation and

1 See IPCC, Working Group II Contribution to the Fifth Assessment Report, Climate Change 2014: Impacts, Adaptation and Vulnerability, Summary for Policymakers (2014), at 13.

2 Ibid., at 6, citing disruption of food production resulting from climate-related extremes, including cyclones.

3 Paris Agreement (adopted 12 December 2015), UnfCcc, 'Adoption of the Paris Agreement', FCCC/CP/2015/L.9/Rev.1, 21 (2015).

4 Kiribati, the Solomon Islands, Tuvalu, and Vanuatu are all classified as LDCs under the UN framework. See UN Committee for Development Policy, List of Least Developed Countries (as of June 2017), <www.un.org/development/desa/dpad/wp-content/uploads/sites/45/publica tion/ldc_list.pdf $>$.

5 United Nations University Institute for Environment and Human Security, World Risk Report (2015), at 46.

6 Pacific Islands Development Forum, Suva Declaration on Climate Change (4 September 2015), Third Annual Summit, Suva, Fiji, 2-4 September 2015, para. 1.

7 See Report of the Office of the United Nations High Commissioner for Human Rights on the Relationship Between Climate Change and Human Rights, Un Human Rights Council, Tenth Session, A/HRC/10/61 (2009) (hereinafter OHсHR Report); and UN Human Rights Council, Resolution 18/22, Human Rights and Climate Change, Eighteenth Session, A/HRC/RES/18/22 (2011) (hereinafter UN Human Rights Council Resolution). 
population displacement, ${ }^{8}$ in the absence of legal protection or recognition of environmental refugees. ${ }^{9}$ Yet, engagement by states in the region with the core international human rights treaties and mechanisms remains remarkably limited.

Three principal restrictive factors to the ratification and implementation of the aforementioned treaties can be identified: capacity; the costs of reporting and implementation; ${ }^{10}$ and a perceived conflict between Pacific customs and human rights. The last of these will not be explored in detail here, as it has already been the subject of extensive study.11 (It should nevertheless be noted that the majority of South Pacific sids have embedded a number of civil and political rights in their national constitutions, ${ }^{12}$ and examples can be found of domestic courts giving precedence to human rights where they have come into conflict with custom. ${ }^{13}$ )

On the basis of the doctrinal and empirical evidence gathered, I argue that institutional barriers constitute the most substantial barriers to the engagement of South Pacific sIDS with international human rights treaties. These institutional barriers should be tackled as a matter of priority in order to allow greater recourse to justice to climate-vulnerable states and their peoples. I define institutional barriers narrowly, as those financial and human-capacity factors restricting the ability of national institutions to provide for substantive and procedural protection of the rights enshrined in the core international human rights treaties. Attempts to define institutions within the political sciencesthrough, for example, historical or rational-choice institutionalism ${ }^{14}$-along

8 Elizabeth Ferris, Michael M. Cernea, and Daniel Petz, 'On the Front Line of Climate Change and Displacement: Learning with and from Pacific Island Countries', The Brookings Institution: London School of Economics Project on Internal Displacement (2011), at 18. Convention Relating to the Status of Refugees (28 July 1951), 189 UNTS 137, art. 1(2), requires a 'well-founded fear of being persecuted' due to 'race, religion, nationality, membership of a particular social group or political opinion' in order for a person to qualify for legal protection. Environmental threats fall outside of the scope of the existing framework.

10 Dejo Olowu, International Law: A Textbook for the South Pacific (CDPublishing.org, 2010), at 182 .

11 See, for example, New Zealand Law Commission, Converging Currents: Custom and Human Rights in the Pacific, Study Paper 17 (September 2006); and Sue Farran, Human Rights in the South Pacific: Challenges and Changes (Abingdon: Routledge, 2009).

12 United Nations Office of the High Commissioner for Human Rights, Regional Office for the Pacific and Pacific Islands Forum Secretariat, Ratification of International Human Rights Treaties: Added Value for the Pacific Region, Discussion paper (July 2009), at vii.

13 See, for example, John Noel v. Obed Toto [1995] Supreme Court of Vanuatu vusc 3, Civil Case 018 of 1994 (19 April 1995).

14 Peter Hall and Rosemary Taylor, 'Political Science and the Three New Institutionalisms', 44(5) Political Studies 936 (1996), at 937-946. 
with those in the sociological literature encompassing more 'normative and cultural-cognitive'15 elements, are numerous and highly contested. While such debates are crucial to determining the origins, purpose, and impact of institutions on social life, such questions are beyond the scope of the present analysis, which is limited to dismantling ascertainable material barriers to national-government engagement with the treaties. The definition of institutional barriers I have adopted is therefore context-specific.

In this article I go further than the existing literature that examines the human-rights structures and challenges in the South Pacific ${ }^{16}$ or the humanrights obligations forming the basis of claims of state responsibility in respect of extreme weather events. ${ }^{17} \mathrm{I}$ do so by exploring the entrenched barriers to government engagement with human-rights mechanisms in the context of climate change. The article is comprised of a multi-level law-and-policy analysis that draws on supporting empirical data collected in the South Pacific region to outline the gaps in existing international approaches and examine current institutional challenges. I also suggest ways in which effective international assistance could be provided to overcome these challenges, in order to strengthen the legal position of climate-vulnerable sids.

The qualitative empirical data for this article was collected between May and July 2016, in Port Vila (Vanuatu) and Suva (Fiji), as part of a broader research project examining climate justice and the potential legal responses to climate change in the South Pacific. Semi-structured interviews were conducted with thirty-one persons working in the areas of human rights, justice, and climate change. Seven of the interviewees were employed by un bodies, three by Pacific regional organizations, eleven were NGO-based, seven worked for national government departments, and three were in private legal firms. The data was thematically coded according to key human-rights and climatejustice indicators, ranging from 'loss and damage' to 'access to justice'. For this article, I have used the most relevant coded data themes, namely those relating to institutional capacity, funding challenges, government engagement with

15 Richard Scott, Institutions and Organisations: Ideas and Interests (3rd ed., Los Angeles: Sage, 2008), at 48.

16 See Farran, supra note 11.

17 See Fitilagi Fa'anunu, 'A Breach of Fundamental Human Rights as the Legal Basis for Reparations for Climate Change-Damages and Injuries under International Law: Case Study of Ha'apai Islands (Tonga) Following Cyclone Ian', 1 Journal of South Pacific Law A-41 (2015); and Calvy Aonima and Shivanal Kumar, 'Could Vanuatu Claim Reparations under International Law for Damages Sustained from Cyclone Pam?', 1 Journal of South Pacific Law A-23 (2015). 
the international human rights framework, and the linkages between human rights and climate change.

\section{Institutional Barriers: Capacity and Funding}

I begin by examining the approach adopted by UN bodies at the international level to recognized institutional barriers in the fields of climate change and human rights in order to enable an identification of the weaknesses of the responses to date. The specific challenges faced at the regional level by states in the South Pacific will then be discussed, taking into account the relevant support provided by regional organizations. Lastly, a national-level analysis of the institutional barriers to human-rights engagement in Vanuatu and Fiji will inform the conclusions drawn in relation to the efficacy of the international and regional responses as well as the suggested future steps for effective engagement by governments.

\subsection{Approach of $U N$ Bodies}

At the international level, UN environment and human-rights bodies have widely acknowledged that institutional challenges faced by many LDCs and sIDS serve to restrict effective engagement with the legal frameworks of climate change and human rights. In the human-rights field, these challenges are primarily discussed in the context of encouraging ratification and implementation of the core conventions. Worldwide, ratification of the core conventions and optional protocols remains far from universal. ${ }^{18} \mathrm{~A}$ striking example of the hurdles still facing the establishment of universal human-rights protection can be found in the very small number of ratifications of the Optional Protocol to the International Covenant on Economic, Social, and Cultural Rights, ${ }^{19}$ which contains the core complaints mechanisms for socio-economic rights.

The lack of legal protection afforded to socio-economic rights by South Pacific sids should be of particular concern with respect to climate change in light of the findings of the онснR and Special Rapporteur on Human Rights

18 Some 65 States have ratified 9 or fewer of the 18 international human rights treaties and optional protocols as of 8 September 2017: see OHCHR, Status of Ratification Interactive Dashboard, <http://indicators.ohchr.org/>.

19 The ICESCR Optional Protocol containing individual and inter-state complaints procedures (as of 8 September 2017), boasts a mere 22 state parties: See United Nations Treaty Collection, Status of Treaties, Chapter Iv, Human Rights, <https://treaties.un.org/Pages/ ViewDetails.aspx?src=TREATY\&mtdsg_no=IV-3-a\&chapter $=4 \&$ clang $=\_$en $>$. 
and the Environment that climate change will have a significant impact on the enjoyment of people's rights to health, food, and housing. ${ }^{20}$ The curtailment of the rights to self-determination and cultural development of climatevulnerable communities, particularly those facing displacement or complete inundation in low-lying $\operatorname{siDs},{ }^{21}$ is a further pressing issue in this respect. The number of ratifications of the core instruments is steadily increasing globally, particularly in the wake of the establishment of the Universal Periodic Review (UPR) process, currently in its third cycle; nevertheless, in the case of Pacific siDs, the number remains low. ${ }^{22}$

Formal accession to the instruments and effective engagement with the obligations contained therein, through reporting and implementation at the national level, are of course distinct matters. It has been noted that a lack of capacity or political will has caused some state parties to fail to fully engage, ${ }^{23}$ evidenced most clearly in their non-compliance with reporting obligations. At present, there are nine core human rights conventions and optional protocols that carry reporting obligations, ${ }^{24}$ in addition to the UPR process. They cumulatively place a significant burden on national governments and the regional and international institutions responsible for supporting and monitoring compliance. The overlapping nature of the reporting obligations has been found to challenge even those state parties with established human-rights infrastructure and a high level of institutional capacity. ${ }^{25}$ The burdens being borne by states already facing capacity and funding challenges are understandably considered to be disproportionate to the benefits gained at the international level through ratification or compliance. As a result, many states have failed

20 OHCHR report, supra note 7; and Report of the Special Rapporteur on the issue of human rights obligations relating to the enjoyment of a safe, clean, healthy and sustainable environment, un Human Rights Council, Thirty-first session Agenda Item 3, A/HRC/31/52 (1 February 2016) (hereinafter Special Rapporteur Report), at 7.

21 OHCHR report, supra note 7 , at 14-15.

22 Secretariat of the Pacific Community and United Nations Office for the High Commissioner for Human Rights, Human Rights in the Pacific: A situational analysis (2016), at 3, <www.spc.int/wp-content/uploads/2016/12/Human-right-Pacific.pdf>.

23 United Nations International Human Rights Instruments, Concept Paper on the High Commissioner's Proposal for a Unified Standing Treaty Body, Report by the Secretariat, HRI/MC/2006/CRP.1 (2006) (hereinafter UN Concept Paper), at 7, para. 16.

24 See Compliance by States Parties with their Reporting Obligations to International Human Rights Treaty Bodies, Note by the Secretariat, 29th meeting of Chairs of the Human Rights Treaty Bodies, HRI/MC/2017/2 (2017), at 2.

25 UN Concept Paper, supra note 23, para. 16. 
to report fully or have experienced significant delays in complying with their various reporting obligations. ${ }^{26}$

The funding being channelled into O HCHR capacity-building programmes, ${ }^{27}$ along with the General Assembly's proposal for designated human-rights capacity-building officers to be stationed in regional branches, ${ }^{28}$ are positive steps aimed at facilitating more widespread implementation and compliance by states. The report of the Secretary-General on the status of the humanrights treaty-body system concluded that these activities can be seen to have increased states' willingness to engage with the process. ${ }^{29}$ Nevertheless, the OHCHR found that only 16 per cent of the state parties to the nine core human rights treaties are able to meet their reporting obligations and deadlines. ${ }^{30}$

The Paris Agreement contains a clause on financial assistance for developing countries. It provides that the needs of those states most vulnerable to climate-change impacts that also face 'significant capacity constraints', ${ }^{31}$ specifically LDCs and SIDS, should be taken into account. The Paris Agreement is the first climate treaty to make reference to human rights, albeit only in the preamble. ${ }^{32}$ Coupled with the climate-finance bodies' low level of engagement with human rights, ${ }^{33}$ this constitutes evidence that human-rights considerations are new to the climate change framework.

26 See UnOHCHR, 'Reporting compliance by State parties to the human rights treaty bodies' (30 June 2016), <www.ohchr.org/Documents/Issues/HRIndicators/Reporting_Compli ance.pdf $>$.

27 See the Un Voluntary Fund for Technical Cooperation in the Field of Human Rights, Report of the Chair of the Board of Trustees of the United Nations Voluntary Fund for Technical Cooperation in the Field of Human Rights, UN Human Rights Council, A/HRC/34/74 (2017) (hereinafter UNHRC Board of Trustees Report).

28 UN General Assembly, Background Paper in Support of the Intergovernmental Process of the General Assembly on Enhancing the Effective Functioning of the Human Rights Treaty Body System, A/68/6o6 (2013), at Section E.

29 UN General Assembly, Status of the Human Rights Treaty Body System: Report of the Secretary-General, 71st Session, A/71/118 (18 July 2016), at 4, (hereinafter Report of the Secretary-General).

30 UNOHCHR, National Mechanisms for Reporting and Follow-up: A Study of Engagement with International Human Rights Mechanisms, HR/PUB/16/1/Add.1 (2016), at 5, <www .ohchr.org/Documents/Publications/HR_PUB_16_1_NMRF_Study.pdf>.

31 Paris Agreement, supra note 3, art. 9(4).

32 Ibid., Preamble.

33 The climate finance bodies have primarily engaged with human rights as safeguards in respect of mitigation or adaptation projects. See, for example, Global Environment Facility, GEF Policies on Environmental and Social Safeguard Standards and Gender Mainstreaming, 
The UN Environment Programme (now called UN Environment) has shed further light on the human-rights implications of climate change, along with the potential duties and obligations which may arise in this contextfor example, in relation to the duty of states to respect, promote, and fulfil rights. ${ }^{34}$ UNEP's 2015 report explores the need for 'rights safeguards' in climateadaptation and mitigation projects, ${ }^{35}$ for human rights to be taken into account in UNFCCC COP decisions, ${ }^{36}$ and for the protection of procedural rights in environmental matters. ${ }^{37}$ The report further acknowledges the existence of institutional capacity limitations ${ }^{38}$ and the need for national implementation of human rights. ${ }^{39}$ However, the specific challenges associated with the ratification of, and reporting on, the core human-rights conventions are not addressed.

UNEP's report's suggestion that human-rights bodies could be included in loss-and-damage discussions, ${ }^{40}$ along with the acknowledgement in the Paris Agreement that human rights should be considered and promoted in climate action, ${ }^{41}$ constitute tentative first steps towards the integration of human rights into climate policy. UNEP's report underlines the need for increased financial support for those developing countries most vulnerable to climate change, stating that the Copenhagen climate-finance pledge of $\$ 100$ billion per year by $2020^{42}$ will not be a sufficient amount for the years following $2020 .^{43}$ The integration of funding for human-rights capacity-building into climatefinance sources, in tandem with the scaling-up of such contributions, may offer a means to break the entrenched institutional barriers that restrict both

GEF/C.40/10/Rev.1 (2011); and Green Climate Fund, Mainstreaming Gender, <www.green climate.fund/how-we-work/mainstreaming-gender >.

Michael Burger and Jessica Wentz, Climate Change and Human Rights, United Nations Environment Programme in cooperation with Columbia Law School Sabin Center for Climate Change Law (Nairobi: UNON, 2015), at VIII and 15.

Ibid., at 26 .

36 Ibid., at viII.

37 Ibid., at 16-18.

38 Ibid., at 33 .

39 Ibid., at 42.

40 Ibid., at 41.

41 Paris Agreement, supra note 3, Preamble.

42 UNFCCC, Copenhagen Accord, Decision 2/CP.15, FCCC/CP/2009/11/Add.1 (18 December 2009), at para. 8 .

Burger and Wentz, supra note 34, at 41. 
adaptive capacity ${ }^{44}$ and engagement with the core international human rights treaties. $^{45}$

\subsection{Institutional Barriers in the South Pacific}

As shown in Figure 1, ratification of the core human-rights treaties in the South Pacific remains low. Efforts towards the establishment of a Pacific regional human-rights framework, which has been called for by regional bodies making the case for the creation of a Pacific charter or commission, ${ }^{46}$ have stalled. Consequently, the facilitation of effective engagement by national governments with the international mechanisms is all the more important.

Concerted support through bilateral aid, multilateral development banks, civil society, and regional organizations is being provided to South Pacific states for climate adaptation, disaster-risk resilience, and capacity building. ${ }^{47}$ In the

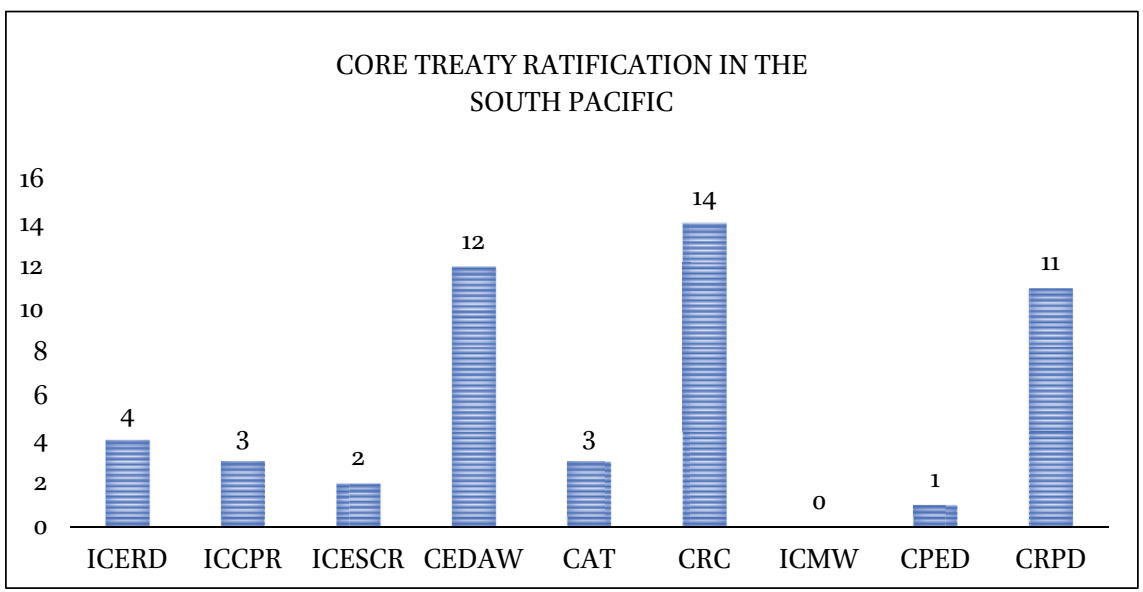

FIGURE 1 Ratifications by fourteen South Pacific SIDS of the nine core human rights treaties. The fourteen states are: Cook Islands, Fiji, Kiribati, Marshall Islands, Federated States of Micronesia, Nauru, Niue, Papua New Guinea, Palau, Samoa, Solomon Islands, Tonga, Tuvalu, and Vanuatu.

TREATY DATA SOURCED FROM THE UNITED NATIONS, AS AT 18 SEPTEMBER 2017.

44 Ibid., at 32.

45 See Unoнchr Regional Office for the Pacific and PIF Secretariat, supra note 12.

46 Regional Human Rights Mechanisms: Pathways for the Pacific, Pacific Regional Rights Resource Team (Suva: Secretariat of the Pacific Community, 2012).

47 Vanuatu Climate Finance Forum Outcomes Document, National Advisory Board on Climate Change and Disaster Risk Reduction of the Government of Vanuatu (1 December 2016), at 1, <www.nab.vu/news/outcomes-vanuatu-climate-finance-forum>. 
human-rights field, the Secretariat of the Pacific Community (SPC), through its Regional Rights Resource Team (RRRT), based in Suva-founded with the goal 'to strengthen the capacity of the Pacific region to promote principles of human rights and good governance ${ }^{\prime 48}$ — provides training and technical advice to governments to facilitate engagement with the core human rights conventions ${ }^{49}$ and the fulfilment of UPR reporting obligations. ${ }^{50}$ The Pacific Islands Forum Secretariat has in place a political governance and security programme that aims to promote consideration of 'ratification of core human rights treaties.' ${ }^{51}$ Such initiatives find further support in the work of UN organizations active in the region, including OHCHR, ${ }^{52} \mathrm{UNICEF}^{53}$ and UN Women. ${ }^{54}$ OHCHR, in particular, has offered technical support through a treaty-body capacity-building programme, in recognition of the reporting challenges faced by many states; it provides assistance with common core documents, treaty-specific reports, and so-called National Mechanisms for Reporting and Follow-Up. 55

Resource constraints are a commonly cited reason for South Pacific governments choosing to refrain from ratifying more instruments. For example, OHCHR and the Pacific Islands Forum Secretariat concluded that 'most Pacific Island countries believe that they do not have sufficient resources to implement human rights treaties'; 56 they instead channel resources into highpriority concerns, including adapting to climate change. ${ }^{57}$ Governments in the

48 P.I. Jalal and J. Madraiwiwi (eds.), Pacific Human Rights Law Digest, vol. I PHRLd (Suva: Pacific Regional Rights Resource Team, 2005), at vi.

49 Secretariat of the Pacific Community RRRT, Human Rights Programme, Ratification and Implementation of Human Rights Treaties Project, <http://rrrt.spc.int/projects/ ratification-reporting >.

5o Secretariat of the Pacific Community RRRT, Human Rights Programme, Universal Periodic Review Project, <http://rrrt.spc.int/projects/universal-periodic-review >.

51 Pacific Islands Forum Secretariat, Political Governance and Security Programme, <http:// www.forumsec.org/pages.cfm/political-governance-security/>.

The UnонснR Regional Office for the Pacific's mandate provides assistance to governments to 'actively engage with the international human rights mechanisms: the treaty bodies, special procedures and in particular the UPR process'; $<$ http://pacific.ohchr.org/>. See UnICEF, Pacific Island Countries Policy, Advocacy, Planning and Evaluation Programme (PAPE) which has an objective to ensure regular reporting by Pacific states on CRC implementation; <www.unicef.org/pacificislands/overview_15282.html>.

See un Women, Pacific Women's Access to Justice and Human Rights Initiative, focusing on the implementation of CEDAw; <http://asiapacific.unwomen.org/en/countries/fiji/ advance-gender-justice >.

онснв Regional Office for the Pacific, онснR Quarterly Update (January-March 2016), $<$ http://pacific.ohchr.org/>.

56 OHCHR Regional Office for the Pacific and PIF Secretariat, supra note 12, at 9.

57 Ibid. 
region have treated climate change and human rights as separate policy issues requiring distinct budgets and institutional frameworks, with the exception of safeguards for adaptation projects. ${ }^{58}$

Institutional capacity limitations further restrict governments' ability to enact national implementation measures or comply with reporting obligations. As one regional organization employee observed in relation to the low number of ratifications: 'One major challenge is reporting. Many governments are not actually against the treaties, they just don't want to take on additional reporting obligations. ${ }^{59}$ Challenges of compliance with reporting obligations continue to be experienced in the South Pacific, with twelve out of fourteen sids having one or more overdue reports, and with Papua New Guinea having six overdue reports. ${ }^{60}$ Only two states, the Marshall Islands and Niue, were fully compliant as at March 2017.61

Climate finance in the South Pacific has primarily been allocated for disaster-risk resilience, technological capacity building, and energy projects, ${ }^{62}$ in line with the core funding priorities of the UNFCCC's Least Developed Countries Fund ${ }^{63}$ and Special Climate Change Fund. ${ }^{64}$ The overlap between climate change and human-rights activities has thus far been limited to the fields of women's and children's rights, in line with the markedly higher engagement in the region with the Convention on the Elimination of All Forms of

58 See Government of the Republic of Fiji, Republic of Fiji National Climate Change Policy (Suva: Secretariat of the Pacific Community, 2012), which makes no mention of human rights; and Government of the Republic of Vanuatu, Vanuatu Climate Change and Disaster Risk Reduction Policy 2016-203o (Suva: Secretariat of the Pacific Community, 2015), which refers to human rights briefly in the context of 'ensuring that adaptation and risk reduction initiatives incorporate the rights, priorities and needs of individuals' (at 19).

59 Interview with Regional Organization Employee in Suva, Fiji (11 July 2016).

6o Compliance by States Parties with their Reporting Obligations to International Human Rights Treaty Bodies: Note by the Secretariat, United Nations International Human Rights Instruments, UN Doc. HRI/MC/2017/2 (2 May 2017), at 4-5.

61 Ibid.

62 The GCF (as of 7 September 2017) lists South Pacific projects in the following sectors: hydropower development in the Solomon Islands; flood management in Samoa; climate data generation in Vanuatu; renewable energy assessments in Cook Islands, Tonga, Republic of Marshall Islands, Federated States of Micronesia, Papua New Guinea, Nauru, and Samoa; coastal adaptation in Tuvalu; and water management in Fiji: $<$ www.greencli mate.fund/what-we-do/projects-programmes $>$.

63 See UnFCCC Decision 3/CP.11, 'Further guidance for the operation of the Least Developed Countries Fund', FCCC/CP/2005/5/Add.1 (30 March 2006), at 10-11.

64 See UnfCcc, Decision $7 /$ CP.7, 'Funding under the Convention', 8th plenary meeting (10 November 2001), at para. 2. 
Discrimination Against Women (CEDAW) and the Convention on the Rights of the Child (CRC). ${ }^{65}$ As one interviewee from a regional organization observed: 'We work with women, children, and persons with disability because this is one of the more highly ratified conventions within the Pacific, so [we are] trying to work with our governments towards being able to live up to the obligations they've been a party to.'66 The willingness to engage with CEDAW and CRC obligations has been evidenced through national-level reforms aimed at the promotion of these rights, ${ }^{67}$ giving cause for encouragement that, in spite of perceived tensions with custom, ${ }^{68}$ where increased institutional and financial support is provided, active engagement will take place.

\subsection{Barriers Emerging at the National Level: Vanuatu and Fiji}

Concerns over institutional capacity and funding constraints have been outlined by climate and human-rights stakeholders at the domestic level. The second-cycle UPR reports for both Vanuatu and Fiji make reference to a lack of available resources and the need for increased capacity-building support. ${ }^{69} \mathrm{Fi}-$ ji's UPR report notably refers to the challenge posed by the competing demands on the country's resources in guaranteeing socio-economic rights, given the 'constraints on state resources and the competing demands of civil and political rights. ${ }^{70}$ The need for the government to provide adequate funding for the

65 The CRC has received universal ratification; CEDAW is lacking ratifications from only two of the fourteen South Pacific states analysed. Based on fourteen Pacific sids: the Cook Islands, Federated States of Micronesia, Fiji, Kiribati, Marshall Islands, Nauru, Niue, Palau, Papua New Guinea, Samoa, Solomon Islands, Tonga, Tuvalu, and Vanuatu; see UN Treaty Collection, Status of Treaties (as of 18 September 2017), <https://treaties.un.org/Pages/ Treaties.aspx?id=4\&subid=A\&clang=_en $>$.

66 Interview with Regional Organization Employee in Suva, Fiji (7 July 2016).

67 At the national level, see for example: Family Protection Act 2008 [No. 28] (Vanuatu), Family Law (Amendment) Decree 2012, Decree No. 34 of 2012 (Fiji), and Marriage Act (Amendment) Decree 2009, Decree No. 26 of 2009 (Fiji).

68 Pacific Handbook on Human Rights Treaty Implementation, un Development Programme Pacific Centre, (2012), at 37-38, <www.undp.org/content/dam/rbap/docs/Research\%20 $\& \% 20$ Publications/governance/PC_DG_Human_Rights_Treaty_Implementation_Hand book.pdf $>$ (hereinafter UNDP Pacific Handbook).

69 See UN General Assembly, National Report submitted in accordance with paragraph 5 of the annex to Human Rights Council Resolution 16/21: Fiji, A/HRC/WG.6/20/FJI/1 (2014) (hereinafter Fiji Second-cycle UPR Report); and Un General Assembly, National Report submitted in accordance with paragraph 5 of the annex to Human Rights Council Resolution 16/21: Vanuatu, A/HRC/WG.6/18/vUT/1 (2013) (hereinafter Vanuatu Second-cycle UPR Report).

$70 \quad$ Ibid., para. 144. 
effective functioning of the country's Human Rights and Anti-Discrimination Commission was underlined in the second-cycle report. ${ }^{71}$ Civil-society interviewees in Fiji observed that capacity and funding constraints were exacerbated by the additional budgetary and institutional pressures in the aftermath of Cyclone Winston in 2016. One participant remarked that the 'government ... right now is trying to decrease its budget from other allocations that it has and to direct that to the ... rebuilding that we will have to do after this cyclone. ${ }^{72}$ The recognition by civil-society actors of those challenges has prompted them to offer increased support, for example in the monitoring of projects, expressed by one participant in the following terms: 'So we implement and ... because ... they are under-resourced and ... often understaffed, we try and also monitor'73 the community-level projects.

Technical capacity, specifically in respect of climate change and human rights, was flagged as a constraint by an employee of a civil-society organization: 'Funding a project and bringing in the specific expert to actually conduct a specific component towards climate change [by] looking at human rights and so forth, that is kind of a limitation in Fiji for us. ${ }^{74}$ A potential solution to this challenge would be to integrate human-rights capacity building into existing climate change programmes, albeit with some initial outlay to retrain personnel. This ties in with the express focus of Pacific regional organizations on garnering additional financial resources for capacity building for adaptation. ${ }^{75}$

The benefits of harmonization within the climate and disaster-risk fields are already being extolled at the national level, notably through the establishment of the Vanuatu Ministry of Climate Change, which brought together the Departments of Environment, Energy, and Climate Change Adaptation, as well as the Department of Meteorology and Geohazards and the National Disaster Management Office, under one roof, to foster closer collaboration among them. That was accompanied with the establishment of a National Advisory Board on Climate Change and Disaster Risk Reduction, which invited participation from civil-society organizations. As one government employee

\footnotetext{
71 Ibid., para. 88.

72 Interview with Civil Society Organization Employee in Suva, Fiji (12 July 2016).

73 Ibid.

74 Interview with Civil Society Organization Employee in Suva, Fiji (12 July 2016).

75 See Pacific Adaptation to Climate Change Fiji Islands: Report of In Country Consultations, Secretariat of the Pacific Regional Environment Programme (SPREP), <www.sprep.org/ att/publication/ooo668_FijiReport_NationalPACCReport_Final.pdf $>$; and Coping with Climate Change in the Pacific Island Region, SPC-GIZ 2016 Annual report (CCCPIR), Vanuatu programme, <www.nab.vu/sites/default/files/documents/SPC\%20GIZ\%2oCCCPIR\%20 $2016 \% 20$ Annual\%2oReport.pdf >.
} 
remarked: 'Quite severe human-resources capacity limitations'76 persist in Vanuatu and elsewhere in the Pacific, yet the Ministry has managed to bring together 'issues of climate and disaster-risk reduction in a much more streamlined, efficient and strong way' ${ }^{77}$ The establishment of the Ministry of Climate Change was cited by the government of Vanuatu in its second-cycle UPR report as a relevant achievement contributing to the fulfilment of Vanuatu's human rights obligations. ${ }^{78}$

Both Fiji and Vanuatu discuss climate change and the need for adaptation assistance in relation to the fulfilment of their international human rights obligations for the UPR. In Fiji's second-cycle report, climate change is discussed more indirectly, in the context of social development and its implications for social well-being and rights generally. ${ }^{79}$ Climate change impacts, particularly the increasing intensity of flooding and cyclones, are discussed in the report in the context of the need for mitigation and disaster-risk reduction. ${ }^{80}$ The report poignantly underlines Fiji's status as a developing country with 'scarce resources and competing obligations' ${ }^{81}$ However, the report contains no discussion of the specific human-rights implications of climate change or the harmonization of climate change and human rights in capacity-building terms.

In Vanuatu, both the second-cycle UPR report and the qualitative data I collected in the course of the empirical study tell a similar story, with significant challenges in institutional capacity and funding facing the establishment of effective climate change policies and human-rights protections. The report notably cites the specific constraints of a lack of human resources, a lack of financial assistance to properly address areas needing reform, a lack of understanding and expectation of the UN human rights conventions, and a lack of internal capacity to incorporate human rights conventions into domestic legislation,', ${ }^{82}$ in relation to the fulfilment of Vanuatu's international human rights obligations. Vanuatu thoroughly integrated climate change into the report, citing the need for additional assistance for adaptation and capacity development, including through reference to 'particularly vulnerable groups including women, children and persons with disabilities', ${ }^{83}$ whose rights are

\footnotetext{
76 Interview with National Government Official, Port Vila, Vanuatu (17 May 2016).

77 Ibid.

78 Vanuatu Second-cycle UPR Report, supra note 69, at 16.

79 Fiji Second-cycle UPR Report, supra note 69, para. 91.

8 o Ibid., paras. 136-138.

81 Ibid., para. 137.

82 Vanuatu Second-cycle UPR Report, supra note 69, at para. 90.

83 Ibid., para. 94.
} 
likely to be more severely impacted. These observations are accompanied by a request from the Vanuatu government to the international community for 'additional technical and financial assistance for the implementation of human rights conventions. ${ }^{84}$

In all, some 24 out of 28 participant organizations in the empirical study made observations on the existence of human or institutional capacity constraints, while 25 discussed funding constraints or the need more broadly for increased funding for projects. There is, however, evidence of the willingness of South Pacific governments to engage with the conventions to which they are already party and towards which they receive significant funding support, for example through broad-based reform and the enactment of new domestic legislation in accordance with their CEDAW obligations. ${ }^{85}$ This further reinforces the view that institutional challenges, rather than a simple lack of political will, are to blame for the lack of effective engagement in the region. The ratification of instruments, where possible, has had the effect of generating support for further action; however, breaking the initial barriers to formal engagement is the logical first step. Indeed, many participants discussed their current involvement in capacity-building and training schemes, and viewed such initiatives as valuable, underlining the need for further support.

Institutional capacity and funding challenges in respect of sIDs' engagement with the international human rights regime are widely acknowledged at the international, regional, and national levels. But while at the international level human rights are engaged with at arm's length, as guiding principles and safeguards in climate action, at the national level, in Fiji and Vanuatu's UPR reports, clear links are drawn between capacity building in the fields of climate change and human rights.

\section{Breaking Down Institutional Barriers}

This section encompasses several conclusions on how sIDs could overcome the institutional barriers impeding their effective engagement with

84 Ibid., para. 93 .

85 See UN Committee on the Elimination of All Forms of Discrimination Against Women, Concluding observations on the combined fourth and fifth periodic reports of Vanuatu, CEDAW/C/vUT/CO/4-5 (9 March 2016); and Committee on the Elimination of Discrimination against Women, Concluding observations of the Committee on the Elimination of Discrimination against Women: Fiji, Addendum Information provided by the Government of Fiji on the Follow-up to the Concluding Observations of the Committee, CEDAw/ C/FJI/CO/4/Add.1 (2 August 2012). 
the international human rights framework. The conclusions are split into two categories. The first concerns an improved international funding strategy, while the second details key steps to build and maximize existing in-country capacity.

\section{1}

\section{Funding Strategy}

3.1.1 Channelling Climate Finance into Protection of Human Rights Integrating strengthened human-rights protection into climate responses as a central rather than ancillary safeguarding component will require a merging of strategies and available financial resources at the regional and international levels. At the international level there needs to be a recognition of the need for climate finance to include initiatives aimed at strengthening human-rights protections; for, until now, with respect to climate-vulnerable sIDs, the finance has principally focused on adaptation projects. ${ }^{86}$ The aim would be to increase the availability of funding for capacity-building in human rights, sourced not only from donor states but also from the private sector. A significant injection of support of this kind may have the effect of breaking entrenched institutional barriers to engagement with the international human rights framework in the South Pacific, particularly as climate change dominates the regional policy agenda and therefore already benefits from greater institutional focus.

To this end, strong cooperation is needed between institutions for climate change and human rights, at both the international and regional levels. The two main international sources of climate finance are the Global Environment Facility and the Green Climate Fund. The Special Climate Change Fund and Least Developed Countries Fund provide additional support. ${ }^{87}$ These climatefinance bodies do not have an express focus on human rights, and indeed adaptation and mitigation projects in receipt of climate finance have come under scrutiny for having adverse impacts on the enjoyment of human rights. ${ }^{88}$ Policies on social safeguarding and gender mainstreaming are in place, ${ }^{89}$ but

86 See Green Climate Fund projects in the South Pacific, supra note 62.

87 UNFCCC, Decision 7/CP.7, 'Funding under the Convention', FCCC/CP/2001/13/Add.1 (2001), $<$ http://unfccc.int/files/cooperation_and_support/financial_mechanism/application/ $\mathrm{pdf} / 7_{-}$cp.7.pdf $>$.

88 See Alyssa Johl and Yves Lador, 'A Human Rights Based Approach to Climate Finance', Friedrich-Ebert Stiftung, (February 2012); and Damilola S. Olawuyi, The Human RightsBased Approach to Carbon Finance (Cambridge: Cambridge University Press, 2016).

89 See Global Environment Facility, GEF policies on environmental and social safeguard standards and gender mainstreaming, GEF/C.40/10/Rev.1 (26 May 2011); and Green Climate Fund, Mainstreaming Gender, <www.greenclimate.fund/how-we-work/mainstreaming -gender>. 
these rarely make reference to human rights, viewing them as ancillary considerations rather than central components of climate-adaptation schemes.

At an institutional level, a formalization of the relationship between climatefinance bodies and organizations focused on human rights is required. Some links already exist among organizations operating in the Pacific. The GEF, for example, recognizes the UNDP, Asian Development Bank, and UNEP, as GEF agencies, ${ }^{90}$ and has links with civil-society organizations through its cso network. Similarly, the GCF has accredited the UNDP and the Secretariat of the Pacific Regional Environment Programme ${ }^{91}$ as entities capable of receiving funds for projects in the region. An ideal candidate to act as an implementing entity would be a body such as the Secretariat of the Pacific Community Regional Rights Resource Team (SPC-RRRT), which has an established programme of human-rights capacity building, a presence in national governments, and an express focus on the impacts of climate change on the enjoyment of human rights. ${ }^{92}$ SPC-RRRT focal officers currently stationed in government departments would be well placed to gather detailed information on the institutional capacity needs of countries, while their established working relationships and their familiarity with government structures would offer efficiency benefits compared with externally appointed actors.

\subsubsection{Bolstering and Broadening the Remit of Existing Human-Rights Funds}

Sources of funding for capacity building with the objective of facilitating effective engagement and implementation of the international human rights framework have already been established under the auspices of the un Human Rights Council. Among them, the Voluntary Fund for Technical Cooperation in the Field of Human Rights was established in 1987 by the UN Commission on Human Rights ${ }^{93}$ to provide funding through voluntary contributions, with the objective of strengthening national and regional bodies and their legal frameworks to implement human rights. ${ }^{94}$ The Fund has supported the provision of human-rights advisers and in-country offices in many countries; however, the only initiative listed for the South Pacific region in 2016 was a human-rights

\footnotetext{
9o Global Environment Facility, GEF Agencies, <www.thegef.org/partners/gef-agencies >.

91 Green Climate Fund, Accredited Entity Directory, <www.greenclimate.fund/how-we -work/tools/entity-directory>.

92 Secretariat of the Pacific Community RRRT, Climate Change and Human Rights Project, $<$ http://rrrt.spc.int/projects/climate-change $>$.

93 Commission on Human Rights, Resolution 1993/87, 'Advisory services and the Voluntary Fund for Technical Cooperation in the Field of Human Rights' (1993), <www.ohchr.org/ EN/Countries/VFTC/Pages/Res_Dec.aspx>. UNHRC Board of Trustees Report, supra note 27, at 3.
} 
adviser stationed in Papua New Guinea. ${ }^{95}$ Only one pledge, by Australia, in the 2016 list of donors and contributors was specifically earmarked for activities in the South Pacific, again in Papua New Guinea; however, this pledge was listed as unpaid. ${ }^{96}$ The Board of Trustees underlined the need to ensure 'more substantial and sustained funding' ${ }^{97}$ of OHCHR programmes overall, in order to enable 'adequate support' 98 to be provided to states.

The UPR Voluntary Fund for Financial and Technical Assistance has a narrower remit, primarily focused on facilitating effective engagement with the UPR process. ${ }^{99}$ The mandate of the UPR Fund includes the development of national capacity and expertise, information-sharing, and co-funding of programmes, with the aim of implementing UPR recommendations. ${ }^{100}$ There is evidence of the UPR Fund providing support more widely in the South Pacific, including to Tuvalu, Tonga, Vanuatu, Fiji, Palau, Papua New Guinea, and the Solomon Islands. ${ }^{101}$ The broadly defined remits of the UPR and Technical Cooperation Funds do not include any express reference to climate change; however, they do underline the need to integrate UPR outcomes into the UN Development Assistance Framework, ${ }^{102}$ as well as the importance of OHCHR contributions towards the attainment of the Sustainable Development Goals. ${ }^{103}$ An indirect link to climate change therefore exists by virtue of the integration of the SDGS into the UNDAF, ${ }^{104}$ and in particular, SDG 13, which demands 'urgent action to combat climate change and its impacts'. ${ }^{105}$

\footnotetext{
95 Ibid., at 15 .

96 Ibid., at 19 .

97 Ibid., at 14, para. 48.

98 Ibid., at para. 48 .

99 UNOHCHR, 'Terms of Reference for the Voluntary Fund for Financial and Technical Assistance for the Implementation of the Universal Periodic Review', <www.lan.ohchr.org/ Documents/HRBodies/UPR/TOR_TF_for_TC_assistance_UPR.pdf > (hereinafter Terms of Reference for the UPR Fund).

100 Ibid.

101 Requests for financial assistance under the Voluntary Fund for Participation in the UPR Mechanism (as of 24 February 2012), <www.ohchr.org/EN/HRBodies/UPR/Documents/ VPUFinancialRequest.pdf>.

102 Terms of Reference for the UPR Fund, supra note 99, para. 6(a).

103 UNHRC Board of Trustees Report, supra note 27, at para. 49.

104 Summary Brief on UN Development Assistance Frameworks (UNDAFs): Status, trends and next generation, UN Development Operations Coordination Office (March 2016), <www .un.org/ecosoc/sites/www.un.org.ecosoc/files/files/en/qcpr/doco-summary-brief-on -undaf-march2016.pdf >.

105 UN General Assembly, Resolution 70/1, 'Transforming our world: the 2030 Agenda for Sustainable Development', A/RES/70/1 (2015), at 14 .
} 
Lastly, the Trust Fund to support the participation of LDCs and sIDS in the work of the Human Rights Council has a mandate to 'enhance the institutional and human capacity'106 of states, including by offering training to governments on the international human rights framework. The fund covers travel expenses for delegations from LDCs and sIDs to attend Human Rights Council sessions in Geneva and offers a three-month fellowship scheme for government officials. ${ }^{107}$ These provisions are beneficial. However, in light of the reliance of this and other funds on voluntary contributions, ${ }^{108}$ the few financial resources they provide would be better channelled into capacity-building programmes at the national level, to be implemented, for example, by Pacific regional organizations. ${ }^{109}$

The lack of harmonization among the trust funds, despite the apparent overlap in their mandates in terms of national-level capacity building, is reflective of the fragmented nature of the human-rights framework itself. The refocusing of funding support to deal with institutional barriers at the national level should be given urgent priority, particularly in respect of the two core covenants (the ICCPR and the ICESCR), thereby providing a baseline of legal protection for many of the rights acknowledged to be at risk from the impacts of climate change. ${ }^{110}$

Harmonization of the trust funds may strengthen their claim to additional funding. They have the advantage of strong institutional links to the international human rights bodies, with ready access to relevant technical expertise. However, the desirability of channelling funding and capacity support through these international funds, as opposed to more directly through regional or national human-rights bodies, is questionable. Regional and national bodies in the South Pacific have established working relationships with government stakeholders, as well as detailed knowledge of the national institutional context. Pacific regional organizations ${ }^{111}$ already provide their own human-rights

106 UN Human Rights Council, Resolution 19/26, 'Terms of reference for the Voluntary Technical Assistance Trust Fund to Support the Participation of Least Developed Countries and Small Island Developing States in the Work of the Human Rights Council', A/HRC/RES/19/26 (10 April 2012).

107 Ibid.

108 See UNHRC Board of Trustees Report, supra note 27, para. 7: 'financial support for OHCHR programmes is not at the required levels to meet needs on the ground; in fact, the funds received through the Voluntary Fund for Technical Cooperation continue to shrink'.

109 See SPC-RRRT and Pacific Island Forum Secretariat, supra notes $5^{0}$ and 51.

110 See OHCHR Report and UN Human Rights Council Resolution, supra note 7.

111 See, for example, programmes of the SPC-R RRT, supra note 50; and Pacific Islands Forum Secretariat, supra note 51 . 
capacity-building support, as do UN in-country offices, ${ }^{112}$ national humanrights institutions, ${ }^{113}$ and government committees. ${ }^{114}$ National human-rights institutions in the South Pacific, although small in number, ${ }^{115}$ could offer the benefit of combining in-depth national knowledge with international standard-setting and support through the Global Alliance of National Human Rights Institutions ${ }^{116}$ and the Asia-Pacific Forum of National Human Rights Institutions. ${ }^{117}$ The HRC trust funds could then play a complementary role in offering additional sources of funding to these regional and national actors, in tandem with new climate-finance sources.

\subsubsection{Integration of Climate-Vulnerability Assessments}

Climate-vulnerability assessments need to be firmly integrated into the allocation of funding for human-rights capacity-building purposes. Such assessments could take as a starting point the IPCC's vulnerability criteria: sensitivity to climate change, potential for harm, and ability to adapt. ${ }^{118}$ Vulnerability will need to be defined in this context through a human-rights lens, taking into account socio-economic factors as well as the availability of human-rights protections at the national level. Factors to be considered may include the number of ratifications of the core international treaties and protocols, the availability of complaints procedures, evidence of national implementing legislation, whether a national human-rights mechanism such as a commission has been

112 See, for example, UNICEF and UN Women Pacific programmes, supra notes 53 and 54, both with offices in Vanuatu and Fiji.

113 See, for example, the Ombudsman of Samoa, <www.ombudsman.gov.ws/>; and Fiji Human Rights and Anti-Discrimination Commission, <www.fhradc.org.fj/ $>$.

114 For example, Vanuatu Human Rights Committee, formally established in 2014, 2014Justice and Community Services Sector Annual Report, Government of the Republic of Vanuatu, Ministry of Justice and Community Services, at 10, <https://mjcs.gov.vu/images/report ing/Annual_Report_2014_v1_04052015.pdf>.

115 UNDP Pacific Handbook, supra note 68, at 66-67.

116 See Global Alliance of National Human Rights Institutions, Chart of the Status of National Institutions (as of 5 August 2016); only Samoa is listed of the fourteen South Pacific SIDS analysed:<www.ohchr.org/Documents/Countries/NHRI/ChartStatusNHRIs.pdf $>$. The Fiji Human Rights Commission gained and subsequently lost international accreditation following the 2006 military coup; see Sonia Cardenas, Chains of Justice: The Global Rise of State Institutions for Human Rights, (Philadelphia: University of Pennsylvania Press, 2014), at 208-209.

117 See Asia Pacific Forum of National Human Rights Institutions, of which the Samoa Ombudsman is a member, <www.asiapacificforum.net/>.

118 IPCC, The Regional Impacts of Climate Change: An Assessment of Vulnerability, Summary for Policymakers (1997), <www.ipcc.ch/pdf/special-reports/spm/region-en.pdf>. 
established, and the availability of a regional human-rights mechanism. In the interests of efficiency, these more tailored assessments could be made part of climate-vulnerability assessments already occurring at the national and regional levels, if necessary with the support of specialized regional coordinators. In the South Pacific, factors including vulnerability to climate impacts, socio-economic risks, and the rarity of human-rights complaints mechanisms, would see states prioritized as recipients of available funding.

Climate-vulnerability assessments could form part of a more comprehensive analytical model which takes into account risks from other significant threats to fundamental rights, such as political instability. However, as climate change represents a multifaceted and severe threat to human rights, it should be incorporated into needs-based assessments for the allocation of funding. The introduction of such assessments, together with the provision of increased funding support through the channelling of climate finance into human-rights capacity building, either as a result of integration into climate-adaptation programmes or through existing human-rights schemes, would lay the groundwork for increased engagement at the regional and national levels.

\subsection{Maximizing In-country Capacity}

3.2.1 Streamlining Reporting Requirements in Respect of ClimateVulnerable sids

Reporting obligations must be streamlined in order to reduce the reporting deficit weighing upon governments in the region and to encourage more effective engagement with the international human rights mechanisms. Successive un High Commissioners for Human Rights have made proposals for reform aimed at harmonizing the work of the various treaty bodies and streamlining the arduous reporting processes. ${ }^{119}$ The most ambitious was a proposal in 2006 for the establishment of a unified standing treaty body (UST), to replace the numerous part-time bodies with a single permanent entity. Increased expert assistance in capacity building at the national level and a single centralized reporting process for all treaty obligations would have been part of it. ${ }^{120}$

The UST was not established, and although UPR went some way to addressing the need for harmonization, it has been introduced in tandem with separate treaty-body reporting, adding to the weight of existing obligations.

119 See UN Concept Paper, supra note 23; and Navanethem Pillay, 'Strengthening the United Nations human rights treaty body system: A report by the United Nations High Commissioner for Human Rights' (June 2012), <http://www2.ohchr.org/english/bodies/HRTD/ docs/HCReportTBStrengthening.pdf $>$.

120 Ibid., UN Concept Paper, at 11. 
Subsequent reform proposals have been far more modest in nature; they include the introduction of simplified reporting procedures ${ }^{121}$ on an optional basis, which may be offered by the human-rights treaty bodies to alleviate the burden on state parties by providing them with a list of specific questions to respond to, thereby streamlining their respective reporting obligations. Simplified reporting procedures have been adopted by the majority of the humanrights treaty bodies, ${ }^{122}$ however their uptake has not been universal.

The modest reforms adopted in the form of common core documents and simplified reporting procedures, whereby states are only obligated to respond to 'lists of issues prior to reporting' (LOIPR) after a comprehensive initial report has been submitted, are insufficient to address the concerns of sIDs facing severe capacity and funding challenges. The fundamental lack of harmonization between the nine core treaty reporting processes, mirrored in the patchy adoption of simplified procedures by their respective Committees (despite calls by the UN General Assembly ${ }^{123}$ ) is symptomatic of an international structure in need of reform. However, in light of the rejection of more fundamental structural reform proposals (most notably the UST ${ }^{124}$ ), the recognition of the unique position of climate-vulnerable SIDS, and the severity of the threat of climate change to the continued enjoyment of a wide range of rights (already acknowledged by the OHCHR and Human Rights Council ${ }^{125}$ ), a targeted streamlining should take place.

The integration of climate-vulnerability assessments would enable the effective engagement of SIDS, and indeed LDCs (for which capacity hurdles are particularly difficult to overcome), with international human-rights protections. By identifying those states particularly vulnerable to the human-rights impacts of climate change, special measures could be taken to accommodate them, both in reporting and capacity building. They could include the development of more restricted LOIPRs for climate-vulnerable states, a grace period for compliance with obligations under the more specialized treaties to enable the prioritization of the ICCPR and ICESCR, or collaboratively agreed exceptions between relevant treaty bodies. Alternatively, special reporting

121 Pillay, supra note 119 , at $47-48$.

122 See, notably, the Committee Against Torture, Human Rights Committee, Committee on the Protection of the Rights of All Migrant Workers and Members of Their Families, Committee on the Rights of Persons with Disabilities, Committee on the Elimination of Discrimination Against Women, and Committee on the Rights of the Child.

123 UN General Assembly, Resolution 68/268, 'Strengthening and enhancing the effective functioning of the human rights treaty body system', A/RES/68/268 (21 April 2014).

124 UN Concept Paper, supra note 23.

125 See $O H C H R$ Report and UN Human Rights Council Resolution, supra note 7. 
procedures could be developed in relation to those conventions containing the rights most widely impacted by climate change; for example, the ICESCR and Optional Protocol containing the rights to health and an adequate standard of living, food, and housing, ${ }^{126}$ as well as the corresponding complaints procedures, could be further prioritized.

3.2 .2

Channelling Support to Existing Regional and National-Level Programmes

OHCHR's capacity-building programme has been found to have led to greater input into the common core documents, more effective dialogue with treaty bodies, and an increased willingness to explore national mechanisms. ${ }^{127}$ The value of existing regional organization schemes in the Pacific, such as the human-rights training provided by the SPC-RRRT to policy-makers, was affirmed by interviewees at the national level. As one government official remarked: 'We have benefitted from those trainings very much ... not only for the awareness of human rights but also for reporting purposes, they've assisted us, ${ }^{128}$ emphasizing moreover that in light of the success of such technical capacity-building 'we are already now fit to do all these human rights trainings by ourselves'.129 It is therefore important to channel support through established regional and national human-rights programmes to avoid duplication and to ensure that existing knowledge and expertise are fully utilized.

At the regional level, Pacific organizations including the SPC-RRRT have undertaken training of civil servants and lawyers, while country offices of UN organizations have provided tailored capacity support and technical advice with respect to their areas of expertise (e.g. UN Women in respect of CEDAW reports and UNICEF in respect of the fulfilment of CRC obligations). However, capacity building of this nature is primarily focused on conventions with a high number of ratifications, for which funding is relatively generous. ${ }^{130}$ The consolidation of existing support, channelling it through designated, centralized agencies, such as human-rights committees or climate change departments at the national level, would be beneficial in this respect. Making financial and technical assistance more readily available for the conduct of national consultations, along with training to allay government concerns about a lack of technical expertise in responding to reporting or implementation obligations, is crucial.

126 Special Rapporteur Report, supra note 20.

127 Report of the Secretary-General, supra note 29, at 4.

128 Interview with National Government Employee, Port Vila, Vanuatu (16 May 2016).

129 Ibid.

130 See, for example, the support provided by UNICEF and UN Women, supra notes 53 and 54 . 
3.2.3 Institutional Harmonization of Climate Change and Human Rights To this end, the active institutional harmonization of human rights and climate change at the national level would offer significant benefits. Such harmonization could take various forms; for example, the creation of posts for human-rights advisers within departments of climate change, or the retraining of personnel engaged in adaptive capacity building to address human-rights protections in tandem. By focusing on climate change stakeholders within government, in collaboration with civil-society organizations, where there are pre-existing relationships of trust with particularly climate-vulnerable communities, the gathering of data on the vulnerability of human rights to climate change would be facilitated. Such personnel could assist in conducting appraisals of the legal protections available to climate-vulnerable communities, including factors such as access to legal information and enforceability of rights.

Not only would harmonization facilitate an increased consideration of the human-rights implications of climate change for communities and individuals, it would offer practical advantages in promoting the coordination of activities previously conducted in institutional silos. This would, in turn, enable national and regional bodies to attract a wider variety of funding. Such integration could further respond to the need for human-rights safeguarding in the design and implementation of mitigation and adaptation projects. The human-rights implications of climate action have become the subject of critique in recent years, ${ }^{131}$ and the safeguarding lens applied by many international bodies is reflected in the Paris Agreement. ${ }^{132}$ If, through the institutional integration of human rights and climate change, international human-rights obligations can be given greater effect within existing projects, governments will have a stronger basis on which to claim compliance in their climate programmes. This, in turn, should help to build trust in national institutions with funding bodies and donors, and may ultimately assist in reducing the lengthy bureaucratic processes often associated with the implementation of externally funded adaptation schemes and the certification of national implementing entities for climate finance.

\section{Conclusion}

I have argued that the firm integration of human rights into climate responses, with capacity-building for engagement with the core international

131 See Johl and Lador, supra note 88; and Olawuyi, supra note 88.

132 Paris Agreement, supra note 3. 
conventions and mechanisms as a central component, would offer many concrete benefits for Pacific sids and their peoples. Beyond the less tangible links to development explored in previous studies, ${ }^{133}$ the availability of complaints mechanisms would both strengthen the bargaining position of these states on the international stage and offer some recourse to justice for individuals, many of whom, in the absence of other mechanisms, face displacement and a wide range of threats with few legal options. The dichotomy that has emerged in international discourse between, on the one hand, the recognition of the relevance of human rights as guiding principles and safeguards in climate action, and, on the other, the lack of legal protection available in many of the world's most climate-vulnerable states, needs to be addressed. The reservations made by Pacific sids to their ratification of the Paris Agreement make reference to the need to preserve international legal protections outside of the climate framework; moreover, the growing importance of human rights as grounds in climate litigation around the globe is evident. ${ }^{134}$

Adaptation and mitigation projects remain crucial; however, in light of the significant impact that climate change will have on the enjoyment of fundamental human rights, coupled with the increasingly severe climate impacts on sIDS, the time has come to pragmatically acknowledge the need to offer recourse to justice to climate-vulnerable states and communities. By developing a new climate-finance strategy with strong links to organizations engaged in human-rights work, integrated rights-based vulnerability assessments, and investment in national-level capacity-building, Pacific sids and other climatevulnerable states can break the long-standing institutional barriers that have prevented their effective engagement with the human-rights framework. The statement of the Vanuatu government in its most recent UPR report 'requesting the international community for additional technical and financial assistance for the implementation of human rights conventions ${ }^{135}$ should be heeded and replicated across SIDS and LDCs. As one interviewee put it: 'When it's to do with culture, environment, people ... livelihoods, those rights are non-negotiable.'136

\footnotetext{
133 See, for example, UNDP Pacific Handbook, supra note 68, at 29-31.

134 Michael Burger and Justin Gundlach, The Status of Climate Change Litigation: A Global Review, un Environment Programme in cooperation with the Sabin Center for Climate Change Law at Columbia University (May 2017), at 31-32.

135 Vanuatu Second-cycle UPR Report, supra note 69, para. 93.

136 Interview with Regional Organization Employee in Suva, Fiji (14 July 2016).
} 